\title{
On a System of Generalized Mixed Equilibrium Problems Involving Variational-Like Inequalities in Banach Spaces: Existence and Algorithmic Aspects
}

\author{
H. Mahdioui ${ }^{1}$ and O. Chadli ${ }^{2}$ \\ ${ }^{1}$ Department of Mathematics, Ibnou Zohr University, Agadir 80000, Morocco \\ ${ }^{2}$ Department of Economics, Ibnou Zohr University, B.P. 8658 Poste Dakhla, Agadir 80000, Morocco \\ Correspondence should be addressed to O. Chadli, ochadli@gmail.com
}

Received 28 January 2012; Accepted 15 June 2012

Academic Editor: Abdellah Bnouhachem

Copyright (C) 2012 H. Mahdioui and O. Chadli. This is an open access article distributed under the Creative Commons Attribution License, which permits unrestricted use, distribution, and reproduction in any medium, provided the original work is properly cited.

\begin{abstract}
We study the existence and the algorithmic aspect of a System of Generalized Mixed Equilibrium Problems involving variational-like inequalities (SGMEPs) in the setting of Banach spaces. The approach adopted is based on the auxiliary principle technique and arguments from generalized convexity. A new existence theorem for the auxiliary problem is established; this leads us to generate an algorithm which converges strongly to a solution of (SGMEP) under weaker assumptions. When the study is reduced to the setting of reflexive Banach spaces, then it can be more relaxed by dropping the coercivity condition. The results obtained in this paper are new and improve some recent studies in this field.
\end{abstract}

\section{Introduction and the Problem Statement}

Let $K$ be a nonempty closed convex subset of a Banach space $X$, and let $F: K \times K \rightarrow \mathbb{R}$ be a real-valued bifunction. By equilibrium problem, in short (EP), we mean the following problem:

(EP) Find $\bar{u} \in K$ such that $F(\bar{u}, v) \geq 0 \quad \forall v \in K$.

Equilibrium problems are suitable and common format for investigation of various applied problems arising in economics, mathematical physics, transportation, communication systems, engineering, and other fields. Moreover, equilibrium problems are closely related with other general problems in nonlinear analysis, such as fixed points, game theory, variational inequality, and optimization problems, see [1-4]. Various kinds of iterative 
algorithms to solve equilibrium problems and variational inequalities have been developed by many authors. There exists a vast literature on the approximation solvability of equilibrium problems and nonlinear variational inequalities using projection type methods, proximal-type methods, or resolvent operator type methods, see [5-11]. We observe that the projection method and its variant forms cannot be applied for constructing iterative algorithms of mixed variational-like inequalities or mixed equilibrium problems involving variational-like inequalities. This fact motivated many authors to develop the auxiliary principle technique to study the existence and algorithm of solutions for variational-like inequalities and its extensions to mixed equilibrium problems, see [12-15]. Kazmi and Khan [16] studied a system of generalized variational-like inequality problems in Hilbert spaces by using the auxiliary principle technique. Recently, Ding and Wang [17] and Ding [18] introduced new iterative algorithms for solving some class of system of generalized mixed variational-like inequalities and system of mixed equilibrium problems involving variationallike inequalities.

In this paper, we study the existence and the algorithmic aspect of a System of Generalized Mixed Equilibrium Problems involving variational-like inequalities (SGMEPs) in the setting of Banach spaces. A new existence theorem for the auxiliary problem is established, this leads us to generate an algorithm which converges strongly to a solution of (SGMEP) under weaker assumptions. When the study is reduced to the setting of reflexive Banach spaces, then it can be more relaxed by dropping the coercivity condition. The results obtained in this paper are new and improve some recent studies in this field.

Throughout this paper, let $I=\{1,2\}$ be an index set. For each $i \in I$, let $X_{i}$ be a Banach space, $X_{i}^{*}$ its dual, $\langle\cdot, \cdot\rangle_{i}$ is the duality pairing between $X_{i}^{*}$ and $X_{i},\|\cdot\|_{i}$ denotes the norm in $X_{i}$ and $X_{i}^{*}$, and let $K_{i}$ be a nonempty closed convex subset of $X_{i}$. We will denote by $\mathcal{C} B\left(X_{i}^{*}\right)$ the family of all nonempty closed and bounded subsets of $X_{i}^{*}$.

For each $i \in I$, let $R_{i}: K_{1} \rightrightarrows \mathcal{C B}\left(X_{1}^{*}\right)$ and $A_{i}: K_{2} \rightrightarrows \mathcal{C B}\left(X_{2}^{*}\right)$ be multivalued mappings, $N_{i}: X_{1}^{*} \times X_{2}^{*} \rightarrow X_{i}^{*}$ and $\eta_{i}: X_{i} \times X_{i} \rightarrow X_{i}$ be single-valued mappings, $F_{i}, \psi_{i}: K_{i} \times K_{i} \rightarrow \mathbb{R}$ be two real-valued functions, and let $w_{i} \in X_{i}^{*}$. We consider the following System of Generalized Mixed Equilibrium Problem involving variational-like inequalities (SGMEP).

Find $\left(\bar{x}_{1}, \bar{x}_{2}\right) \in K_{1} \times K_{2},\left(\bar{u}_{1}, \bar{v}_{1}\right) \in R_{1}\left(\bar{x}_{1}\right) \times A_{1}\left(\bar{x}_{2}\right)$, and $\left(\bar{u}_{2}, \bar{v}_{2}\right) \in R_{2}\left(\bar{x}_{1}\right) \times A_{2}\left(\bar{x}_{2}\right)$ such that

$$
\begin{array}{ll}
F_{1}\left(\bar{x}_{1}, y_{1}\right)+\left\langle N_{1}\left(\bar{u}_{1}, \bar{v}_{1}\right)-w_{1}, \eta_{1}\left(y_{1}, \bar{x}_{1}\right)\right\rangle_{1}+\psi_{1}\left(\bar{x}_{1}, y_{1}\right)-\psi_{1}\left(\bar{x}_{1}, \bar{x}_{1}\right) \geq 0 & \forall y_{1} \in K_{1} ; \\
F_{2}\left(\bar{x}_{2}, y_{2}\right)+\left\langle N_{2}\left(\bar{u}_{2}, \bar{v}_{2}\right)-w_{2}, \eta_{2}\left(y_{2}, \bar{x}_{2}\right)\right\rangle_{2}+\psi_{2}\left(\bar{x}_{2}, y_{2}\right)-\psi_{2}\left(\bar{x}_{2}, \bar{x}_{2}\right) \geq 0 & \forall y_{2} \in K_{2} .
\end{array}
$$

\subsection{Some Special Cases}

(1) If for each $i \in I, X_{i}=X_{i}^{*}=H_{i}$ is a Hilbert space, $K_{i}=H_{i}, F_{i} \equiv 0, w_{i}=0$ and for each $(x, y) \in H_{1} \times H_{2}, R_{i}(x)=x$ and $A_{i}(y)=y$, then problem (1.2) reduces to the problem of finding $\left(\bar{x}_{1}, \bar{x}_{2}\right) \in H_{1} \times H_{2}$ such that

$$
\begin{array}{ll}
\left\langle N_{1}\left(\bar{x}_{1}, \bar{x}_{2}\right), \eta_{1}\left(y_{1}, \bar{x}_{1}\right)\right\rangle_{1}+\psi_{1}\left(\bar{x}_{1}, y_{1}\right)-\psi_{1}\left(\bar{x}_{1}, \bar{x}_{1}\right) \geq 0 & \forall y_{1} \in H_{1} \\
\left\langle N_{2}\left(\bar{x}_{1}, \bar{x}_{2}\right), \eta_{2}\left(y_{2}, \bar{x}_{2}\right)\right\rangle_{2}+\psi_{2}\left(\bar{x}_{2}, y_{2}\right)-\psi_{2}\left(\bar{x}_{2}, \bar{x}_{2}\right) \geq 0 & \forall y_{2} \in H_{2} .
\end{array}
$$

Problem (1.3) has been introduced and studied by Kazmi and Khan in [16]. 
(2) If for each $i \in I, X_{i}$ is a reflexive Banach space, $K_{i}=X_{i}$ and $F_{i} \equiv 0$, then problem (1.2) reduces to the problem of finding $\left(\bar{x}_{1}, \bar{x}_{2}\right) \in X_{1} \times X_{2},\left(\bar{u}_{1}, \bar{v}_{1}\right) \in R_{1}\left(\bar{x}_{1}\right) \times A_{1}\left(\bar{x}_{2}\right)$ and $\left(\bar{u}_{2}, \bar{v}_{2}\right) \in R_{2}\left(\bar{x}_{1}\right) \times A_{2}\left(\bar{x}_{2}\right)$ such that

$$
\begin{array}{ll}
\left\langle N_{1}\left(\bar{u}_{1}, \bar{v}_{1}\right)-w_{1}, \eta_{1}\left(y_{1}, \bar{x}_{1}\right)\right\rangle_{1}+\psi_{1}\left(\bar{x}_{1}, y_{1}\right)-\psi_{1}\left(\bar{x}_{1}, \bar{x}_{1}\right) \geq 0 & \forall y_{1} \in X_{1} \\
\left\langle N_{2}\left(\bar{u}_{2}, \bar{v}_{2}\right)-w_{2}, \eta_{2}\left(y_{2}, \bar{x}_{2}\right)\right\rangle_{2}+\psi_{2}\left(\bar{x}_{2}, y_{2}\right)-\psi_{2}\left(\bar{x}_{2}, \bar{x}_{2}\right) \geq 0 & \forall y_{2} \in X_{2} .
\end{array}
$$

Problem (1.4) has been considered recently by Ding and Wang in [17].

(3) In finite dimensional spaces a particular problem of (1.2) has been considered by Mordukhovich et al. in [19] for finding a common solution of a variational inequality problem and an equilibrium problem by an approach based on an hybrid proximal point algorithm.

The organization of the paper is as follows. In Section 2, we give some definitions and preliminary results that we will need in the sequel. We introduce in Section 3 an auxiliary principle, for the problem studied and we show that under some suitable conditions this problem has a unique solution. Further, by using the auxiliary principle we consider an algorithm to approach the solution of the main problem studied in this paper and discuss its convergence. Finally, we end the paper by some commentaries on the approach used and we give some comparisons with some known results in this direction.

\section{Preliminaries}

In this section, we present some basic concepts, properties, and notations that we will consider in the development of our work. Let $X$ be a real Banach space with norm $\|\cdot\|, X^{*}$ its dual space, and $\langle\cdot, \cdot\rangle$ denote the duality pairing between $X^{*}$ and $X$, and let $K$ be a nonempty closed convex subset of $X$. For a finite subset $A$ of $K$, we denote by $\operatorname{co}(A)$ the convex hull of $A$. Let $\mathcal{C} B\left(X^{*}\right)$ be the family of all nonempty closed and bounded subsets of $X^{*}$, and let $\mathscr{\ell}(\cdot, \cdot)$ be the Hausdorff metric on $\mathcal{C} B\left(X^{*}\right)$ defined for all $A, D \in \mathcal{C} B\left(X^{*}\right)$ by

$$
\mathscr{H}(A, D)=\max \left\{\sup _{a \in A} d(a, D), \sup _{b \in D} d(b, A)\right\},
$$

where $d(a, D)=\inf _{d \in D}\|a-d\|$.

Definition 2.1. A mapping $T: X \rightarrow X^{*}$ is said to be

(i) monotone if and only if $\langle T(x)-T(y), x-y\rangle \geq 0$ for all $x, y \in X$;

(ii) $\alpha$-strongly monotone with $\alpha>0$ if and only if

$$
\langle T(x)-T(y), x-y\rangle \geq \alpha\|x-y\|^{2} \quad \forall x, y \in X
$$

(iii) $L$-Lipschitz continuous if there exists $L>0$ such that

$$
\|T(x)-T(y)\| \leq L\|x-y\| \quad \forall x, y \in X
$$


Definition 2.2. Let $T: X \rightarrow X^{*}$ be a bounded linear operator. $T$ is said to be $\delta$-strongly positive if there exists $\delta>0$ such that

$$
\langle T(x), x\rangle \geq \delta\|x\|^{2}, \quad \forall x \in X
$$

Remark 2.3. One can easily see that if a bounded linear operator $T: X \rightarrow X^{*}$ is $\delta$-strongly positive, then it is $\delta$-strongly monotone and $\|T\|$-Lipschitz continuous, where $\|T\|$ is the operator norm of $T$.

Definition 2.4. Let $X_{1}$ and $X_{2}$ be two Banach spaces with respective norm $\|\cdot\|_{1}$ and $\|\cdot\|_{2}$. A mapping $A_{1}: X_{1} \times X_{2} \rightarrow X_{1}$ is said to be $\left(\beta_{1}, \xi_{2}\right)$-Lipschitz continuous if there exist constants $\beta_{1}, \xi_{2}>0$ such that

$$
\left\|A_{1}\left(x_{1}, y_{1}\right)-A_{1}\left(x_{2}, y_{2}\right)\right\|_{1} \leq \beta_{1}\left\|x_{1}-x_{2}\right\|_{1}+\xi_{2}\left\|y_{1}-y_{2}\right\|_{2} \quad \forall\left(x_{1}, y_{1}\right),\left(x_{2}, y_{2}\right) \in X_{1} \times X_{2} .
$$

Definition 2.5. A mapping $\eta: X \times X \rightarrow X$ is said to be

(i) affine in the second argument if

$$
\eta(y, t x+(1-t) z)=t \eta(y, x)+(1-t) \eta(y, z), \quad \forall t \in[0,1], \forall x, y, z \in K
$$

(ii) $\tau$-Lipschitz continuous if there exists a constant $\tau>0$ such that

$$
\|\eta(x, y)\| \leq \tau\|x-y\|, \quad \forall x, y \in X
$$

Definition 2.6. A real-valued function $\psi: K \times K \rightarrow \mathbb{R}$ is said to be skew-symmetric if for all $x, y \in K$,

$$
\psi(x, x)-\psi(x, y)-\psi(y, x)+\psi(y, y) \geq 0
$$

The skew-symmetric functions have certain properties, see [20], which can be regarded as analogs of the conditions governing the gradient monotonicity and nonnegativity of the second derivative of convex functions.

Definition 2.7. Let $F: K \times K \rightarrow \mathbb{R}$ be a real-valued bifunction. Then,

(i) $F$ is said to be monotone if

$$
F(x, y)+F(y, x) \leq 0, \quad \forall x, y \in K
$$

(ii) $F$ is said to be $\alpha$-strongly monotone if there exists $\alpha>0$ such that

$$
F(x, y)+F(y, x) \leq-\alpha\|x-y\|^{2}, \quad \forall x, y \in K
$$


(iii) $F$ is said to be upper-hemicontinuous if, for all $x, y, z \in K$, the mapping $g:[0,1] \rightarrow$ $\mathbb{R}$ defined by $g(t)=F(t z+(1-t) x, y)$ is upper-semicontinuous.

Remark 2.8. Clearly, strong monotonicity of $F$ implies monotonicity of $F$.

Now, let $S_{F}$ denote the solution set of the equilibrium problem (EP) associated to a bifunction $F$, that is, $S_{F}=\{\bar{x} \in K: F(\bar{x}, y) \geq 0 \forall y \in K\}$. In many situations, we usually need some more information on the structure of the solution set $S_{F}$ when it is nonempty. As a preliminary result that we will need in the sequel, the following Lemma gives some sufficient conditions which insure that $S_{F}$ is convex and closed.

Lemma 2.9. Let $X$ be a Banach space, and let $K$ be a closed convex subset of $X$. Let $F: K \times K \rightarrow \mathbb{R}$ be a real-valued bifunction such that $F(x, x) \geq 0$ for all $x \in K$. Assume that

(i) $F$ is monotone and upper-hemicontinuous;

(ii) for each $x \in K$ fixed, the function $y \mapsto F(x, y)$ is convex and lower semicontinuous. Then, the solution set $S_{F}$ is convex and closed whenever it is nonempty.

Proof. Assume that $S_{F} \neq \emptyset$. Let $\bar{u}, \bar{v} \in S_{F}$ and for $\left.\lambda \in\right] 0,1\left[\right.$ set $x_{\curlywedge}=\lambda \bar{u}+(1-\lambda) \bar{v} \in K$. Let us show that $x_{\curlywedge} \in S_{F}$. Since $\bar{u}, \bar{v} \in S_{F}$, it follows

$$
F(\bar{u}, y) \geq 0, \quad F(\bar{v}, y) \geq 0 \quad \forall y \in K .
$$

From the monotonicity of $F$, one deduces

$$
F(y, \bar{u}) \leq 0, \quad F(y, \bar{v}) \leq 0 \quad \forall y \in K
$$

Therefore, from the convexity of $F$ with respect to its second argument, it follows

$$
F\left(y, x_{\curlywedge}\right) \leq 0, \quad \forall y \in K
$$

Now for $t \in] 0,1\left[\right.$ and $y \in K$, set $x_{t}=t y+(1-t) x_{\lambda} \in K$. Since $F$ is an equilibrium bifunction and $F$ is convex with respect to its second argument, it follows that

$$
0 \leq F\left(x_{t}, x_{t}\right) \leq t F\left(x_{t}, y\right)+(1-t) F\left(x_{t}, x_{\curlywedge}\right) .
$$

Taking account of relation (2.13) with $y=x_{t}$, it follows that $t F\left(x_{t}, y\right) \geq 0$ for all $y \in K$, and therefore since $t>0$

$$
F\left(x_{t}, y\right) \geq 0, \quad \forall y \in K
$$

Since $F$ is upper-hemicontinuous, it follows that

$$
F\left(x_{\lambda}, y\right) \geq \limsup _{t \rightarrow 0} F\left(x_{t}, y\right) \geq 0
$$

Therefore, $x_{\curlywedge} \in S_{F}$, and hence $S_{F}$ is convex. 
Now, let us show that $S_{F}$ is closed. To this aim, let $\left\{x_{n}\right\} \subset S_{F}$ such that $x_{n} \rightarrow \bar{x}$. Let us show that $\bar{x} \in S_{F}$. One has $F\left(x_{n}, y\right) \geq 0$ for all $y \in K$, since $F$ is monotone, it follows that

$$
F\left(y, x_{n}\right) \leq 0, \quad \forall y \in K
$$

From the lower semicontinuity of $F$ with respect to the second argument, it follows that

$$
F(y, \bar{x}) \leq \liminf _{n \rightarrow+\infty} F\left(y, x_{n}\right) \leq 0
$$

By a similar argument as above, one can easily show that $F(\bar{x}, y) \geq 0$ for all $y \in K$. Therefore, $\bar{x} \in S_{F}$, which completes the proof.

In the sequel, we will need the following result that we present in a more general setting and for which we refer to [21].

Lemma 2.10. Let $X$ be a Hausdorff topological vector space and $K$ a closed convex subset of $X$. Consider two real bifunctions $\Phi, \Psi: K \times K \rightarrow \mathbb{R}$ such that

(i) for each $x, y \in K$, if $\Psi(x, y) \leq 0$ then $\Phi(x, y) \leq 0$;

(ii) for each fixed $x \in K$, the function $y \in K \mapsto \Phi(x, y)$ is lower semicontinuous on every compact subset of $K$;

(iii) for each finite subset $A$ of $K$, one has

$$
\sup _{y \in \operatorname{co}(A)} \min _{x \in A} \Psi(x, y) \leq 0
$$

(iv) coercivity: there exists a nonempty compact convex subset $C$ of $X$ such that either (a) or (b) in the following holds

(a) for all $y \in K \backslash C$, there exists $x \in C$ such that $\Phi(x, y)>0$;

(b) there exists $x_{0} \in C$ such that $\forall y \in K \backslash C \Psi\left(x_{0}, y\right)>0$.

Then, there exists $\bar{y} \in C$ such that $\Phi(x, \bar{y}) \leq 0$ for all $x \in K$. Furthermore, the set of solution is compact.

Remark 2.11. (1) Condition (iii) in Lemma 2.10 is much more related to convexity assumptions of the bifunction $\Psi$, see Proposition 2.12 in the following.

(2) If $K$ is compact, then condition (iv) in Lemma 2.10 can be dropped.

The following proposition gives some sufficient conditions which insure condition (iii) in Lemma 2.10.

Proposition 2.12. Suppose that

(i) $\Psi(x, x) \leq 0$ for each $x \in K$;

(ii) for each $y \in K$ fixed, the set $\{x \in K: \Psi(x, y)>0\}$ is convex.

Then, condition (iii) of Lemma 2.10 is staisfied. 
Proof. Suppose by contradiction that condition (iii) of Lemma 2.10 is not satisfied. Then, there exist $x_{1}, \ldots, x_{n} \in K$ and $\lambda_{1}, \ldots, \lambda_{n} \geq 0$, with $\sum_{i=1}^{n} \lambda_{i}=1$, such that $\Psi\left(x_{i}, \sum_{j=1}^{n} \lambda_{j} x_{j}\right)>0$.

Therefore, by setting $y=\sum_{j=1}^{n} \lambda_{j} x_{j}$, it follows from (ii) that $\Psi(y, y)>0$, which contradicts assumption (i).

As a consequence of Lemma 2.10, we obtain the following result on existence of mixed equilibrium problem that we will need in the sequel. We will include its proof for completeness.

Lemma 2.13. Let $X$ be a Banach space and $K$ a closed convex subset of $X$. Let $f, g: K \times K \rightarrow \mathbb{R}$ be two real bifunctions such that

(i) $f(x, x) \geq 0$ for all $x \in K$; $f$ is monotone and upper-hemicontinuous; for each $x \in K$ fixed, the function $y \mapsto f(x, y)$ is convex and lower semicontinuous;

(ii) $g(x, x) \geq 0$ for all $x \in K$; for each $y \in K$ fixed, the function $x \mapsto g(x, y)$ is uppersemicontinuous; for each $x \in K$ fixed, the function $y \mapsto g(x, y)$ is convex and lower semicontinuous;

(iii) coercivity: there exists a nonempty compact convex subset $C$ of $X$ and $y_{0} \in C \cap K$ such that

$$
f\left(x, y_{0}\right)+g\left(x, y_{0}\right)<0 \quad \text { for each } x \in K \backslash C \text {. }
$$

Then, there exists $\bar{x} \in C \cap K$ such that

$$
f(\bar{x}, y)+g(\bar{x}, y) \geq 0 \quad \forall y \in K
$$

Furthermore, the solution set $S_{f, g}$ of the mixed equilibrium problem (2.21) is compact and convex.

Proof. The proof is a direct consequence of Lemma 2.10 by setting

$$
\Phi(x, y)=f(x, y)-g(y, x), \quad \Psi(x, y)=-g(y, x)-f(y, x) .
$$

Remark 2.14. (1) Lemma 2.13 is in fact a slight extension of Theorem 1 in [2] and Theorem 4.5 in [21] where the equilibrium condition $f(x, x)=g(x, x)=0$ has been relaxed by assuming $f(x, x) \geq 0$ and $g(x, x) \geq 0$ for all $x \in K$.

(2) If $X$ is a reflexive Banach space endowed with its weak topology $\sigma\left(X, X^{*}\right)$, then the coercivity condition (iii) in Lemma 2.13 can be replaced by the following condition:

(iii)' there exists $y_{0} \in K$ such that $\lim _{\left\|x-y_{0}\right\| \rightarrow+\infty} g\left(x, y_{0}\right) /\left\|x-y_{0}\right\|=-\infty$.

Ended, let $r_{1}>0$, and set $B\left(y_{0}, r_{1}\right)=\left\{x \in X:\left\|x-y_{0}\right\| \leq r_{1}\right\}$. One has $B\left(y_{0}, r_{1}\right)$ a convex and $\sigma\left(X, X^{*}\right)$-compact subset of $X$. Since $X$ is a reflexive Banach space, $f\left(y_{0}, \cdot\right)$ is lower semicontinuous and $B\left(y_{0}, r\right)$ is weakly compact, it follows that there exists $\alpha_{0} \in \mathbb{R}$ such that $f\left(y_{0}, y\right)>\alpha_{0}$ for all $y \in B\left(y_{0}, r_{1}\right)$. Let $x \in K \backslash B\left(y_{0}, r_{1}\right)$, and set

$$
y=\frac{r_{1}}{\left\|x-y_{0}\right\|} x+\left(1-\frac{r_{1}}{\left\|x-y_{0}\right\|}\right) y_{0} .
$$


Since $f\left(y_{0}, \cdot\right)$ is convex, $y \in B\left(y_{0}, r_{1}\right)$ and $f\left(y_{0}, y_{0}\right) \geq 0$, one deduces

$$
\alpha_{0} \leq \frac{r_{1}}{\left\|x-y_{0}\right\|} f\left(y_{0}, x\right)+\left(1-\frac{r_{1}}{\left\|x-y_{0}\right\|}\right) f\left(y_{0}, y_{0}\right) \quad \forall x \in K \backslash B\left(y_{0}, r_{1}\right) .
$$

It follows that

$$
f\left(y_{0}, x\right) \geq \frac{\left\|x-y_{0}\right\|}{r_{1}}\left(\alpha_{0}-f\left(y_{0}, y_{0}\right)\right)+f\left(y_{0}, y_{0}\right)
$$

Thus,

$$
f\left(y_{0}, x\right) \geq \frac{\left\|x-y_{0}\right\|}{r_{1}}\left(\alpha_{0}-f\left(y_{0}, y_{0}\right)\right), \quad \forall x \in K \backslash B\left(y_{0}, r_{1}\right) .
$$

Since $f$ is monotone, it follows from relation (2.26) that for all

$$
f\left(x, y_{0}\right)+g\left(x, y_{0}\right) \leq g\left(x, y_{0}\right)-\frac{\alpha_{0}-f\left(y_{0}, y_{0}\right)}{r_{1}}\left\|x-y_{0}\right\|
$$

Since $g\left(x, y_{0}\right) /\left\|x-y_{0}\right\| \rightarrow-\infty$ when $\left\|x-y_{0}\right\| \rightarrow+\infty$, then there exists $r_{2}>0$ such that for $x \in K$ with $\left\|x-y_{0}\right\|>r_{2}$ one has

$$
g\left(x, y_{0}\right)-\frac{\alpha_{0}-f\left(y_{0}, y_{0}\right)}{r_{1}}\left\|x-y_{0}\right\|<0
$$

Take $r=\max \left\{r_{1}, r_{2}\right\}$ and set $C=\left\{x \in X:\left\|x-y_{0}\right\| \leq r\right\}$, then from relations (2.27) and (2.28), one deduces that for each $x \in K \backslash C$ one has

$$
f\left(x, y_{0}\right)+g\left(x, y_{0}\right)<0 \text {. }
$$

Hence, condition (iii) in Lemma 2.13 is satisfied.

We end this section by the following result related to the Hausdorff metric that we will need in the sequel and for which we refer to [22].

Lemma 2.15. Let $E$ be a complete metric space and $R: E \rightrightarrows \mathcal{C B}(E)$ a set-valued mapping. Then, for any given $\varepsilon>0$ and any given $x, y \in E$ and $u \in R(x)$, there exists $v \in R(y)$ such that

$$
d(u, v) \leq(1+\varepsilon) \mathscr{\ell}(R(x), R(y)) .
$$

\section{Approximation by an Auxiliary Principle}

In order to get approximate solutions for the system (1.2) of generalized mixed equilibrium problem involving generalized mixed variational-like inequality problems (SGMEP), we 
consider the following auxiliary problem: for $i \in I=\{1,2\}$ and for given mappings $T_{i}: X_{i} \rightarrow$ $X_{i}^{*}, \rho_{i}>0,\left(x_{1}, x_{2}\right) \in K_{1} \times K_{2},\left(u_{1}, v_{1}\right) \in R_{1}\left(x_{1}\right) \times A_{1}\left(x_{2}\right)$, and $\left(u_{2}, v_{2}\right) \in R_{2}\left(x_{1}\right) \times A_{2}\left(x_{2}\right)$,

$$
(\mathrm{AP})\left\{\begin{array}{l}
\text { find }\left(z_{1}, z_{2}\right) \in K_{1} \times K_{2} \text { such that for all } y_{i} \in K_{i} \\
\rho_{i}\left[F_{i}\left(z_{i}, y_{i}\right)+\left\langle N_{i}\left(u_{i}, v_{i}\right)-w_{i}, \eta_{i}\left(y_{i}, z_{i}\right)\right\rangle_{i}+\psi_{i}\left(z_{i}, y_{i}\right)-\psi_{i}\left(z_{i}, z_{i}\right)\right] \\
\quad+\left\langle T_{i}\left(y_{i}-z_{i}\right), z_{i}-x_{i}\right\rangle_{i} \geq 0
\end{array}\right.
$$

In this section, we give some existence results of solutions for the auxiliary problem (AP). The results obtained will be needed in the sequel to generate a unified algorithm to approach solutions of the system (1.2) under some weaker assumptions in comparison with some known results in literature.

Theorem 3.1. For each $i \in I=\{1,2\}$, let $X_{i}$ be a Banach space and $K_{i}$ a nonempty closed convex subset of $X_{i}, F_{i}, \psi_{i}: K_{i} \times K_{i} \rightarrow \mathbb{R}$ two real-valued bifunctions, $T_{i}: X_{i} \rightarrow X_{i}^{*}$ a bounded linear operator, $\rho_{i}>0$ and $\eta_{i}: X_{i} \times X_{i} \rightarrow X_{i}$ single-valued mappings such that

(i) $F_{i}(x, x) \geq 0$ for all $x \in K_{i} ; F_{i}$ is monotone and upper-hemicontinuous; for each $x \in K_{i}$ fixed, the function $y \mapsto F_{i}(x, y)$ is convex and lower semicontinuous;

(ii) $\eta_{i}$ is affine in the first argument and continuous in the second argument such that

$$
\eta_{i}(x, y)+\eta_{i}(y, x)=0, \quad \forall x, y \in K_{i}
$$

(iii) $\psi_{i}$ is skew symmetric and continuous; for each $y \in K_{i}$ fixed, the function $x \mapsto \psi_{i}(x, y)$ is convex;

(iv) $T_{i}$ is $\delta_{i}$-strongly positive;

(v) coercivity: for each $x_{i} \in K_{i}, u_{i} \in X_{1}^{*}$ and $v_{i} \in X_{2}^{*}$, there exists a nonempty compact convex subset $C_{x_{i}, u_{i}, v_{i}}^{i}$ of $X_{i}$ and $y_{i}^{0} \in C_{x_{i}, u_{i}, v_{i}}^{i} \cap K_{i}$ such that $\forall z_{i} \in K_{i} \backslash C_{x_{i}, u_{i}, v_{i}}^{i}$

$$
\rho_{i}\left[F_{i}\left(z_{i}, y_{i}^{0}\right)+\left\langle N_{i}\left(u_{i}, v_{i}\right)-w_{i}, \eta_{i}\left(y_{i}^{0}, z_{i}\right)\right\rangle_{i}+\psi_{i}\left(z_{i}, y_{i}^{0}\right)-\psi\left(z_{i}, z_{i}\right)\right]+\left\langle T_{i}\left(y_{i}^{0}-z_{i}\right), z_{i}-x_{i}\right\rangle<0
$$

Then, the auxiliary problem (AP) has a unique solution.

Proof. The proof of this lemma is a direct application of Lemma 2.13 by considering, for each $i \in I=\{1,2\}$, the bifunctions $f_{i}, g_{i}: K_{i} \times K_{i} \rightarrow \mathbb{R}$ defined by

$$
\begin{gathered}
f_{i}\left(z_{i}, y_{i}\right)=\rho_{i}\left[F_{i}\left(z_{i}, y_{i}\right)+\left\langle N_{i}\left(u_{i}, v_{i}\right)-w_{i}, \eta_{i}\left(y_{i}, z_{i}\right)\right\rangle_{i}+\psi_{i}\left(z_{i}, y_{i}\right)-\psi_{i}\left(z_{i}, z_{i}\right)\right] \\
g_{i}\left(z_{i}, y_{i}\right)=\left\langle T_{i}\left(y_{i}\right)-T_{i}\left(z_{i}\right), z_{i}-x_{i}\right\rangle_{i^{\prime}}
\end{gathered}
$$


where $\left(x_{1}, x_{2}\right) \in K_{1} \times K_{2},\left(u_{1}, v_{1}\right) \in R_{1}\left(x_{1}\right) \times A_{1}\left(x_{2}\right)$, and $\left(u_{2}, v_{2}\right) \in R_{2}\left(x_{1}\right) \times A_{2}\left(x_{2}\right)$ are given. We need only to show that the solution is unique. To this aim, suppose that problem (AP) has two solutions $z_{i}^{1}$ and $z_{i}^{2}$, then for $i \in I$ and for all $z \in K_{i}$, we have

$$
\begin{aligned}
& \rho_{i}\left[F_{i}\left(z_{i}^{1}, z\right)+\left\langle N_{i}\left(u_{i}, v_{i}\right)-w_{i}, \eta_{i}\left(z, z_{i}^{1}\right)\right\rangle_{i}+\psi_{i}\left(z_{i}^{1}, z\right)-\psi_{i}\left(z_{i}^{1}, z_{i}^{1}\right)\right]+\left\langle T_{i}(z)-T_{i}\left(z_{i}^{1}\right), z_{i}^{1}-x_{i}\right\rangle_{i} \geq 0, \\
& \rho_{i}\left[F_{i}\left(z_{i}^{2}, z\right)+\left\langle N_{i}\left(u_{i}, v_{i}\right)-w_{i}, \eta_{i}\left(z, z_{i}^{2}\right)\right\rangle_{i}+\psi_{i}\left(z_{i}^{2}, z\right)-\psi_{i}\left(z_{i}^{2}, z_{i}^{2}\right)\right]+\left\langle T_{i}(z)-T_{i}\left(z_{i}^{2}\right), z_{i}^{2}-x_{i}\right\rangle_{i} \geq 0 .
\end{aligned}
$$

Take $z=z_{i}^{2}$ in relation (3.5) and $z=z_{i}^{1}$ in relation (3.6) and adding the two inequalities, one obtain

$$
\begin{gathered}
\rho_{i}\left[F_{i}\left(z_{i}^{1}\right)+F_{i}\left(z_{i}^{2}, z_{i}^{1}\right)+\left\langle N_{i}\left(u_{i}, v_{i}\right)-w_{i}, \eta_{i}\left(z_{i}^{1}, z_{i}^{2}\right)+\eta_{i}\left(z_{i}^{2}, z_{i}^{1}\right)\right\rangle_{i} \psi_{i}\left(z_{i}^{1}, z_{i}^{2}\right)\right. \\
\left.+\psi_{i}\left(z_{i}^{2}, z_{i}^{1}\right)-\psi_{i}\left(z_{i}^{1}, z_{i}^{1}\right)-\psi_{i}\left(z_{i}^{2}, z_{i}^{2}\right)\right] \geq\left\langle T_{i}\left(z_{i}^{2}-z_{i}^{1}\right), z_{i}^{2}-z_{i}^{1}\right\rangle_{i} .
\end{gathered}
$$

Since for each $i \in I, F_{i}$ is monotone, $\psi_{i}$ is skew symmetric, and $T_{i}$ is $\delta_{i}$-strongly positive, it follows that

$$
0 \geq\left\langle T_{i}\left(z_{i}^{2}-z_{i}^{1}\right), z_{i}^{2}-z_{i}^{1}\right\rangle_{i} \geq \delta_{i}\left\|z_{i}^{1}-z_{i}^{2}\right\|_{i}^{2}
$$

Therefore, $z_{i}^{1}=z_{i}^{2}$ for $i \in I=\{1,2\}$, which completes the proof.

Theorem 3.2. For each $i \in I=\{1,2\}$, let $X_{i}$ be a reflexive Banach space and $K_{i}$ a nonempty closed convex subset of $X_{i}, F_{i}, \psi_{i}: K_{i} \times K_{i} \rightarrow \mathbb{R}$ two real-valued bifunctions, $T_{i}: X_{i} \rightarrow X_{i}^{*}$ a bounded linear operator, $\rho_{i}>0$ and $\eta_{i}: X_{i} \times X_{i} \rightarrow X_{i}$ single-valued mappings such that

(i) $F_{i}(x, x) \geq 0$ for all $x \in K_{i} ; F_{i}$ is monotone and upper-hemicontinuous; for each $x \in K_{i}$ fixed, the function $y \mapsto F_{i}(x, y)$ is convex and lower semicontinuous;

(ii) $\eta_{i}$ is affine in the first argument and continuous in the second argument such that

$$
\eta_{i}(x, y)+\eta_{i}(y, x)=0, \quad \forall x, y \in K_{i}
$$

(iii) $\psi_{i}$ is skew symmetric and continuous; for each $y \in K_{i}$ fixed, the function $x \mapsto \psi_{i}(x, y)$ is convex;

(iv) $T_{i}$ is $\delta_{i}$-strongly positive linear operator.

Then, the auxiliary problem (AP) has a unique solution.

Proof. For each $i \in I$ and given $\left(x_{1}, x_{2}\right) \in K_{1} \times K_{2},\left(u_{1}, v_{1}\right) \in R_{1}\left(x_{1}\right) \times A_{1}\left(x_{2}\right)$, and $\left(u_{2}, v_{2}\right) \in$ $R_{2}\left(x_{1}\right) \times A_{2}\left(x_{2}\right)$, define the following bifunctions $f_{i}, g_{i}: K_{i} \times K_{i} \rightarrow \mathbb{R}$ by

$$
\begin{gathered}
f_{i}\left(z_{i}, y_{i}\right)=\rho_{i}\left[F_{i}\left(z_{i}, y_{i}\right)+\left\langle N_{i}\left(u_{i}, v_{i}\right)-w_{i}, \eta_{i}\left(y_{i}, z_{i}\right)\right\rangle_{i}+\psi_{i}\left(y_{i}, z_{i}\right)-\psi_{i}\left(z_{i}, z_{i}\right)\right] \\
g_{i}\left(z_{i}, y_{i}\right)=\left\langle T_{i}\left(y_{i}\right)-T_{i}\left(z_{i}\right), z_{i}-x_{i}\right\rangle_{i} .
\end{gathered}
$$


One can easily see that conditions (i)-(iii) above imply conditions (i) and (ii) of Lemma 2.13. In order to get the conclusion, we need only to show that the coercivity condition (iii) of Lemma 2.13 is satisfied. To this aim, taking into account Remark 2.14 (2), we need only to show that for some $v_{i}^{0} \in K_{i}$ one has $g_{i}\left(u_{i}, v_{i}^{0}\right) /\left\|v_{i}^{0}-u_{i}\right\|_{i} \rightarrow-\infty$ when $\left\|v_{i}^{0}-u_{i}\right\|_{i} \rightarrow+\infty$. Let $v_{i}^{0} \in K_{i}$. Then,

$$
\begin{aligned}
g_{i}\left(u_{i}, v_{i}^{0}\right) & =\left\langle T_{i}\left(v_{i}^{0}\right)-T_{i}\left(u_{i}\right), u_{i}-x_{i}\right\rangle_{i} \\
& =\left\langle T_{i}\left(v_{i}^{0}-u_{i}\right), u_{i}-v_{i}^{0}\right\rangle_{i}+\left\langle T_{i}\left(v_{i}^{0}-u_{i}\right), v_{i}^{0}-x_{i}\right\rangle_{i} \\
& =-\left\langle T_{i}\left(v_{i}^{0}-u_{i}\right), v_{i}^{0}-u_{i}\right\rangle_{i}+\left\langle T_{i}\left(v_{i}^{0}-u_{i}\right), v_{i}^{0}-x_{i}\right\rangle_{i} \\
& \leq-\delta\left\|v_{i}^{0}-u_{i}\right\|_{i}^{2}+\left\|T_{i}\right\|\left\|v_{i}^{0}-u_{i}\right\|\left\|_{i}\right\| v_{i}^{0}-x_{i} \|_{i}
\end{aligned}
$$

Therefore,

$$
\frac{g_{i}\left(u_{i}, v_{i}^{0}\right)}{\left\|v_{i}^{0}-u_{i}\right\|_{i}} \leq-\delta\left\|v_{i}^{0}-u_{i}\right\|_{i}+\left\|T_{i}\right\|\left\|v_{i}^{0}-x_{i}\right\|_{i} .
$$

It follows that $g_{i}\left(u_{i}, v_{i}^{0}\right) /\left\|v_{i}^{0}-u_{i}\right\|_{i} \rightarrow-\infty$ when $\left\|v_{i}^{0}-u_{i}\right\|_{i} \rightarrow+\infty$ which completes the proof.

Remark 3.3. Theorem 3.2 improves recent results given by Ding [18, Theorem 3.1] since the bifunction $F_{i}$ is not needed to be $\delta_{i}$-Lipschitz continuous and weakly upper semicontinuous with respect to the first argument. We mention also that all the results obtained in [18] are under the assumption $\operatorname{int}\left\{y_{i} \in K_{i}, \psi_{i}\left(y_{i}, y_{i}\right)<\infty\right\}=\operatorname{int} K_{i} \neq \emptyset$; in our approach, this assumption is not needed.

Theorem 3.2 shows that the auxiliary problem (AP) has a unique solution; we can define the following general iterative method to approach the solution of system (1.2) of generalized mixed equilibrium problem involving variational-like inequalities (SGMEP).

Algorithm 3.4. For a given $\left(x_{1}^{0}, x_{2}^{0}\right) \in K_{1} \times K_{2},\left(u_{1}^{0}, v_{1}^{0}\right) \in R_{1}\left(x_{1}^{0}\right) \times A_{1}\left(x_{2}^{0}\right)$, and $\left(u_{2}^{0}, v_{2}^{0}\right) \in R_{2}\left(x_{1}^{0}\right) \times$ $A_{2}\left(x_{2}^{0}\right)$. By Theorem 3.1, the auxiliary problem (AP) has a unique solution $\left(x_{1}^{1}, x_{2}^{1}\right) \in K_{1} \times K_{2}$, that is, for each $i \in I$, we have

$$
\begin{aligned}
& \rho_{i}^{1}\left[F_{i}\left(x_{i}^{1}, y_{i}\right)+\left\langle N_{i}\left(u_{i}^{0}, v_{i}^{0}\right)-w_{i}, \eta_{i}\left(y_{i}, x_{i}^{1}\right)\right\rangle_{i}+\psi_{i}\left(x_{i}^{1}, y_{i}\right)-\psi_{i}\left(x_{i}^{1}, x_{i}^{1}\right)\right] \\
& \quad+\left\langle T_{i}\left(y_{i}\right)-T_{i}\left(x_{i}^{1}\right), x_{i}^{1}-x_{i}^{0}\right\rangle_{i} \geq 0 \quad \forall y_{i} \in K_{i} .
\end{aligned}
$$

Since for each $i \in I, u_{i}^{0} \in R_{i}\left(x_{i}^{0}\right) \in \mathcal{C} B\left(X_{1}^{*}\right)$, and $v_{i}^{0} \in A_{i}\left(x_{2}^{0}\right) \in \mathcal{C B}\left(X_{2}^{*}\right)$, by Lemma 2.15, there exist $u_{i}^{1} \in R_{i}\left(x_{1}^{1}\right)$ and $v_{i}^{1} \in A_{i}\left(x_{2}^{1}\right)$ such that

$$
\begin{gathered}
\left\|u_{i}^{1}-u_{i}^{0}\right\|_{1} \leq(1+1) \mathscr{\ell}_{1}\left(R_{i}\left(x_{1}^{1}\right), R_{i}\left(x_{1}^{0}\right)\right) \\
\left\|v_{i}^{1}-v_{i}^{0}\right\|_{2} \leq(1+1) \mathscr{\ell}_{2}\left(A_{i}\left(x_{2}^{1}\right), A_{i}\left(x_{2}^{0}\right)\right),
\end{gathered}
$$

where $\mathscr{\ell}_{1}$ and $\mathscr{\ell}_{2}$ are the Hausdorff metrics on $\mathcal{C B}\left(X_{1}^{*}\right)$ and $\mathcal{C B}\left(X_{2}^{*}\right)$, respectively. 
By using Theorem 3.1 again, the auxiliary problem (AP) has a unique solution $\left(x_{1}^{2}, x_{2}^{2}\right) \in K_{1} \times K_{2}$ such that

$$
\begin{aligned}
& \rho_{i}^{2}\left[F_{i}\left(x_{i}^{2}, y_{i}\right)+\left\langle N_{i}\left(u_{i}^{1}, v_{i}^{1}\right)-w_{i}, \eta_{i}\left(y_{i}, x_{i}^{2}\right)\right\rangle_{i}+\psi_{i}\left(x_{i}^{2}, y_{i}\right)-\psi_{i}\left(x_{i}^{2}, x_{i}^{2}\right)\right] \\
& +\left\langle T_{i}\left(y_{i}\right)-T_{i}\left(x_{i}^{2}\right), x_{i}^{2}-x_{i}^{1}\right\rangle_{i} \geq 0, \quad \forall y_{i} \in K_{i} .
\end{aligned}
$$

By induction, we can construct an iterative algorithm to compute the approximate solution for the system (1.2) as follows: for given $\left(x_{1}^{0}, x_{2}^{0}\right) \in K_{1} \times K_{2},\left(u_{1}^{0}, v_{1}^{0}\right) \in R_{1}\left(x_{1}^{0}\right) \times A_{1}\left(x_{2}^{0}\right)$, and $\left(u_{2}^{0}, v_{2}^{0}\right) \in R_{2}\left(x_{1}^{0}\right) \times A_{2}\left(x_{2}^{0}\right)$, there exist sequences $\left\{x_{1}^{n}\right\},\left\{x_{2}^{n}\right\},\left\{u_{1}^{n}\right\},\left\{u_{2}^{n}\right\},\left\{v_{1}^{n}\right\}$, and $\left\{v_{2}^{n}\right\}$ such that for each $i \in I$

$$
\begin{gathered}
\left\|u_{i}^{n+1}-u_{i}^{n}\right\|_{1} \leq\left(1+\frac{1}{n+1}\right) \mathscr{L}_{1}\left(R_{i}\left(x_{1}^{n+1}\right), R_{i}\left(x_{1}^{n}\right)\right), \quad u_{i}^{n} \in R_{i}\left(x_{1}^{n}\right), \\
\left\|v_{i}^{n+1}-v_{i}^{n}\right\|_{2} \leq\left(1+\frac{1}{n+1}\right) \mathscr{\ell}_{2}\left(A_{i}\left(x_{2}^{n+1}\right), A_{i}\left(x_{2}^{n}\right)\right), \quad v_{i}^{n} \in A_{i}\left(x_{2}^{n}\right), \\
\rho_{i}^{n+1}\left[F_{i}\left(x_{i}^{n+1}, y_{i}\right)+\left\langle N_{i}\left(u_{i}^{n}, v_{i}^{n}\right)-w_{i}, \eta_{i}\left(y_{i}, x_{i}^{n+1}\right)\right\rangle_{i}+\psi_{i}\left(x_{i}^{n+1}, y_{i}\right)-\psi_{i}\left(x_{i}^{n+1}, x_{i}^{n+1}\right)\right] \\
+\left\langle T_{i}\left(y_{i}\right)-T_{i}\left(x_{i}^{n+1}\right), x_{i}^{n+1}-x_{i}^{n}\right\rangle_{i} \geq 0 \quad \forall y_{i} \in K_{i}, n=0,1,2, \ldots
\end{gathered}
$$

The following convergence analysis is presented for the algorithm above.

Theorem 3.5. Under the hypotheses of Theorem 3.2, further assume that for each $i \in I$,

(i) $F_{i}$ is $\sigma_{i}$-strongly monotone and upper-hemicontinuous; $N_{i}$ is $\left(\beta_{i}, \xi_{i}\right)$-mixed Lipschitz continuity; $R_{i}$ is $k_{i}$-d $\mathscr{L}_{1}$-Lipschitz continuous, and $A_{i}$ is $\mu_{i}$-d ${ }_{2}$-Lipschitz continuous;

(ii) $\eta_{i}$ is $\tau_{i}$-Lipschitz continuous;

(iii) the sequence $\left\{\rho^{n}\right\}_{n \in \mathbb{N}}$ of positive real numbers is increasing and $\lim _{n \rightarrow+\infty} \rho_{n}=+\infty$.

Furthermore, assume that the following condition holds:

$$
\left(C_{1}\right)\left\{\begin{array}{l}
\Lambda=\max \left\{\theta_{1}+\theta_{2}, \vartheta_{1}+\vartheta_{2}\right\}<1, \text { where } \\
\theta_{1}=\frac{\tau_{1} \beta_{1} k_{1}}{\sigma_{1}}, \quad \theta_{2}=\frac{\tau_{2} \beta_{2} k_{2}}{\sigma_{2}}, \\
\vartheta_{1}=\frac{\tau_{1} \xi_{1} \mu_{1}}{\sigma_{1}}, \quad \vartheta_{2}=\frac{\tau_{2} \xi_{2} \mu_{2}}{\sigma_{2}} .
\end{array}\right.
$$

Then, the sequences $\left\{x_{1}^{n}\right\},\left\{x_{2}^{n}\right\},\left\{u_{1}^{n}\right\},\left\{u_{2}^{n}\right\},\left\{v_{1}^{n}\right\}$, and $\left\{v_{2}^{n}\right\}$ generated by Algorithm 3.4 converge strongly to $\bar{x}_{1}, \bar{x}_{2}, \bar{u}_{1}, \bar{v}_{1}, \bar{u}_{2}$, and $\bar{v}_{2}$, respectively, where $\left(\bar{u}_{1}, \bar{v}_{1}\right) \in T_{1}\left(\bar{x}_{1}\right) \times A_{1}\left(\bar{x}_{2}\right),\left(\bar{u}_{2}, \bar{v}_{2}\right) \in$ $T_{2}\left(\bar{x}_{1}\right) \times A_{2}\left(\bar{x}_{2}\right)$, and $\left(\bar{x}_{1}, \bar{x}_{2}, \bar{u}_{1}, \bar{v}_{1}, \bar{u}_{2}, \bar{v}_{2}\right)$ is a solution of the System of Generalized Mixed Equilibrium Problem involving variational-like in equalities (1.2). 
Proof. By the definition of Algorithm 3.4, we have for $i \in I$,

$$
\begin{gathered}
\rho_{i}^{n}\left[F_{i}\left(x_{i}^{n}, y_{i}\right)+\left\langle N_{i}\left(u_{i}^{n-1}, v_{i}^{n-1}\right)-w_{i}, \eta_{i}\left(y_{i}, x_{i}^{n}\right)\right\rangle_{i}+\psi_{i}\left(x_{i}^{n}, y_{i}\right)-\psi_{i}\left(x_{i}^{n}, x_{i}^{n}\right)\right] \\
+\left\langle T_{i}\left(y_{i}\right)-T_{i}\left(x_{i}^{n}\right), x_{i}^{n}-x_{i}^{n-1}\right\rangle_{i} \geq 0 \quad \forall y_{i} \in K_{i}, \\
\rho_{i}^{n+1}\left[F_{i}\left(x_{i}^{n+1}, y_{i}\right)+\left\langle N_{i}\left(u_{i}^{n}, v_{i}^{n}\right)-w_{i}, \eta_{i}\left(y_{i}, x_{i}^{n+1}\right)\right\rangle_{i}+\psi_{i}\left(x_{i}^{n+1}, y_{i}\right)-\psi_{i}\left(x_{i}^{n+1}, x_{i}^{n+1}\right)\right] \\
+\left\langle T_{i}\left(y_{i}\right)-T_{i}\left(x_{i}^{n+1}\right), x_{i}^{n+1}-x_{i}^{n}\right\rangle_{i} \geq 0 \quad \forall y_{i} \in K_{i} .
\end{gathered}
$$

By considering $y_{i}=x_{i}^{n+1}$ in relation (3.18) and $y_{i}=x_{i}^{n}$ in relation (3.19), and taking into account $\eta_{i}\left(x_{i}^{n+1}, x_{i}^{n}\right)=-\eta_{i}\left(x_{i}^{n}, x_{i}^{n+1}\right)$, one obtains by adding the two inequalities

$$
\begin{aligned}
F_{i}\left(x_{i}^{n+1},\right. & \left.x_{i}^{n}\right)+F_{i}\left(x_{i}^{n}, x_{i}^{n+1}\right)+\left\langle N_{i}\left(u_{i}^{n-1}, v_{i}^{n-1}\right)-N_{i}\left(u_{i}^{n}, v_{i}^{n}\right), \eta_{i}\left(x_{i}^{n+1}, x_{i}^{n}\right)\right\rangle_{i} \\
& +\psi_{i}\left(x_{i}^{n}, x_{i}^{n+1}\right)+\psi_{i}\left(x_{i}^{n+1}, x_{i}^{n}\right)-\psi_{i}\left(x_{i}^{n}, x_{i}^{n}\right)-\psi_{i}\left(x_{i}^{n+1}, x_{i}^{n+1}\right) \\
& +\frac{1}{\rho_{i}^{n}}\left\langle T_{i}\left(x_{i}^{n+1}-x_{i}^{n}\right), x_{i}^{n}-x_{i}^{n-1}\right\rangle_{i} \\
& -\frac{1}{\rho_{i}^{n+1}}\left\langle T_{i}\left(x_{i}^{n}-x_{i}^{n+1}\right), x_{i}^{n}-x_{i}^{n+1}\right\rangle_{i} \geq 0 .
\end{aligned}
$$

Since $F_{i}$ is $\sigma_{i}$-monotone, $\psi_{i}$ is skew-symmetric, and $T_{i}$ is $\delta_{i}$-strongly positive and $\left\|T_{i}\right\|$ Lispchitz continuous, it follows from relation (3.20) that

$$
\begin{aligned}
& \left\|N_{i}\left(u_{i}^{n-1}, v_{i}^{n-1}\right)-N_{i}\left(u_{i}^{n}, v_{i}^{n}\right)\right\|\left\|_{i}\right\| \eta_{i}\left(x_{i}^{n+1}, x_{i}^{n}\right)\left\|+\frac{\left\|T_{i}\right\|}{\rho_{i}^{n}}\right\| x_{i}^{n+1}-x_{i}^{n}\left\|_{i}\right\| x_{i}^{n}-x_{i}^{n-1} \|_{i} \\
& \quad \geq\left[\sigma_{i}+\frac{\delta_{i}}{\rho_{i}^{n+1}}\right]\left\|x_{i}^{n}-x_{i}^{n+1}\right\|_{i}^{2} .
\end{aligned}
$$

Note that $N_{1}$ is $\left(\beta_{1}, \xi_{1}\right)$-mixed Lipschitz continuous, $R_{1}$ is $k_{1}$ - $\mathscr{L}_{1}$-Lipschitz continuous, and $A_{1}$ is $\mu_{1}-\mathscr{L}_{2}$-Lipschitz continuous, it follows by Algorithm 3.4

$$
\begin{aligned}
\left\|N_{i}\left(u_{i}^{n-1}, v_{i}^{n-1}\right)-N_{i}\left(u_{i}^{n}, v_{i}^{n}\right)\right\|_{i} \leq & \beta_{1}\left\|u_{i}^{n-1}-u_{i}^{n}\right\|_{1}+\xi_{1}\left\|v_{i}^{n-1}-v_{i}^{n}\right\|_{2} \\
\leq & \beta_{1}\left(1+\frac{1}{n}\right) \mathscr{H}_{1}\left(R_{1}\left(x_{1}^{n-1}\right), R_{1}\left(x_{1}^{n}\right)\right) \\
& +\xi_{1}\left(1+\frac{1}{n}\right) \mathscr{H}_{2}\left(R_{1}\left(x_{2}^{n-1}\right), R_{1}\left(x_{2}^{n}\right)\right) \\
\leq & \beta_{1} k_{1}\left(1+\frac{1}{n}\right)\left\|x_{1}^{n-1}-x_{1}^{n}\right\|_{1}+\xi_{1} \mu_{1}\left(1+\frac{1}{n}\right)\left\|x_{2}^{n-1}-x_{2}^{n}\right\|_{2} .
\end{aligned}
$$


Since $\eta_{1}$ is $\tau_{1}$-Lipschitz continuous, it follows from relation (3.21) considered for $i=1$ that

$$
\begin{aligned}
{\left[\sigma_{1}+\frac{\delta_{1}}{\rho_{1}^{n+1}}\right]\left\|x_{1}^{n}-x_{1}^{n+1}\right\|_{1} \leq } & {\left[\tau_{1} \beta_{1} k_{1}\left(1+\frac{1}{n}\right)+\frac{\left\|T_{1}\right\|}{\rho_{1}^{n}}\right]\left\|x_{1}^{n-1}-x_{1}^{n}\right\|_{1} } \\
& +\tau_{1} \xi_{1} \mu_{1}\left(1+\frac{1}{n}\right)\left\|x_{2}^{n-1}-x_{2}^{n}\right\|_{2} .
\end{aligned}
$$

Hence,

$$
\left\|x_{1}^{n}-x_{1}^{n+1}\right\|_{1} \leq \theta_{1 n}\left\|x_{1}^{n-1}-x_{1}^{n}\right\|_{1}+\vartheta_{1 n}\left\|x_{2}^{n-1}-x_{2}^{n}\right\|_{2^{\prime}}
$$

with

$$
\theta_{1 n}=\frac{\left[\rho_{1}^{n+1} \tau_{1} \beta_{1} k_{1}(1+1 / n)+\rho_{1}^{n+1}\left\|T_{1}\right\| / \rho_{1}^{n}\right]}{\left[\rho_{1}^{n+1} \sigma_{1}+\delta_{1}\right]}, \quad \vartheta_{1 n}=\frac{\rho_{1}^{n+1} \tau_{1} \xi_{1} \mu_{1}(1+1 / n)}{\left[\rho_{1}^{n+1} \sigma_{1}+\delta_{1}\right]}
$$

Similarly, by the assumptions on $F_{2}, N_{2}, \eta_{2}, R_{2}, A_{2}$, and $T_{2}$, it follows from relation (3.21) considered for $i=2$ that

$$
\left\|x_{2}^{n}-x_{2}^{n+1}\right\|_{2} \leq \theta_{2 n}\left\|x_{1}^{n-1}-x_{1}^{n}\right\|_{1}+\vartheta_{2 n}\left\|x_{2}^{n-1}-x_{2}^{n}\right\|_{2}
$$

with

$$
\theta_{2 n}=\frac{\left[\rho_{2}^{n+1} \tau_{2} \beta_{2} k_{2}(1+1 / n)\right]}{\left[\rho_{2}^{n+1} \sigma_{2}+\delta_{2}\right]}, \quad \vartheta_{2 n}=\frac{\rho_{2}^{n+1} \tau_{2} \xi_{2} \mu_{2}(1+1 / n)+\rho_{2}^{n+1}\left\|T_{2}\right\| / \rho_{2}^{n}}{\left[\rho_{2}^{n+1} \sigma_{2}+\delta_{2}\right]} .
$$

Adding the inequalities (3.24) and (3.26), we obtain

$$
\begin{aligned}
\left\|x_{1}^{n}-x_{1}^{n+1}\right\|_{1}+\left\|x_{2}^{n}-x_{2}^{n+1}\right\|_{2} & \leq\left(\theta_{1 n}+\theta_{2 n}\right)\left\|x_{1}^{n-1}-x_{1}^{n}\right\|_{1}+\left(\vartheta_{1 n}+\vartheta_{2 n}\right)\left\|x_{2}^{n-1}-x_{2}^{n}\right\|_{2} \\
& \leq \Lambda_{n}\left(\left\|x_{1}^{n-1}-x_{1}^{n}\right\|_{1}+\left\|x_{2}^{n-1}-x_{2}^{n}\right\|_{2}\right)
\end{aligned}
$$

where $\Lambda_{n}=\max \left\{\theta_{1 n}+\theta_{2 n}, \vartheta_{1 n}+\vartheta_{2 n}\right\}$.

On $X_{1} \times X_{2}$, let us consider the norm $\|\cdot\|_{*}$ defined by $\|(x, y)\|_{*}=\|x\|_{1}+\|y\|_{2}$ for all $(x, y) \in X_{1} \times X_{2}$, that is, $\left(X_{1} \times X_{2},\|\cdot\|_{*}\right)$ is a Banach space. It follows from relation (3.28) that

$$
\left\|\left(x_{1}^{n}, x_{2}^{n}\right)-\left(x_{1}^{n+1}, x_{2}^{n+1}\right)\right\|_{*} \leq \Lambda_{n}\left\|\left(x_{1}^{n-1}, x_{2}^{n-1}\right)-\left(x_{1}^{n}, x_{2}^{n}\right)\right\|_{*} .
$$

Taking account of the assumptions, it is easy to see that $\Lambda_{n} \rightarrow \Lambda$ as $n \rightarrow \infty$. From condition $\left(C_{1}\right)$ (relation (3.17)), we know that $0<\Lambda<1$. Hence, there exist $\Lambda_{0} \in(0,1)$ and $n_{0}>0$ such that $\Lambda_{n} \leq \Lambda_{0}<1$ for all $n \geq n_{0}$. Therefore, it follows from (3.29) that

$$
\left\|\left(x_{1}^{n}, x_{2}^{n}\right)-\left(x_{1}^{n+1}, x_{2}^{n+1}\right)\right\|_{*} \leq \Lambda_{0}\left\|\left(x_{1}^{n-1}, x_{2}^{n-1}\right)-\left(x_{1}^{n}, x_{2}^{n}\right)\right\|_{*} .
$$


This implies that $\left\{\left(x_{1}^{n}, x_{2}^{n}\right)\right\}$ is a Cauchy sequence in $X_{1} \times X_{2}$. Thus, $\left(x_{1}^{n}, x_{2}^{n}\right)$ converges strongly to some $\left(\bar{x}_{1}, \bar{x}_{2}\right) \in K_{1} \times K_{2}$.

By Algorithm 3.4 and the Lipschitz continuity assumption on $R_{1}, R_{2}, A_{1}$, and $A_{2}$, we have

$$
\begin{aligned}
& \left\|u_{i}^{n+1}-u_{i}^{n}\right\|_{1} \leq\left(1+\frac{1}{n+1}\right) \mathscr{\ell}_{1}\left(R_{i}\left(x_{1}^{n+1}\right), R_{i}\left(x_{1}^{n}\right)\right) \leq k_{i}\left(1+\frac{1}{n+1}\right)\left\|x_{1}^{n+1}-x_{1}^{n}\right\|_{1^{\prime}} \\
& \left\|v_{i}^{n+1}-v_{i}^{n}\right\|_{2} \leq\left(1+\frac{1}{n+1}\right) \mathscr{\ell}_{2}\left(A_{i}\left(x_{2}^{n+1}\right), A_{i}\left(x_{2}^{n}\right)\right) \leq \mu_{i}\left(1+\frac{1}{n+1}\right)\left\|x_{2}^{n+1}-x_{2}^{n}\right\|_{2} .
\end{aligned}
$$

It follows, for each $i \in I$, that $\left\{u_{i}^{n}\right\}$ is a Cauchy sequence in $X_{1}^{*}$ and $\left\{v_{i}^{n}\right\}$ is a Cauchy sequence in $X_{2}^{*}$. Thus, there exists $\left(\bar{u}_{i}, \bar{v}_{i}\right) \in X_{1}^{*} \times X_{2}^{*}$ such that $\left(u_{i}^{n}, x_{i}^{n}\right)$ converges strongly to $\left(\bar{u}_{i}, \bar{v}_{i}\right)$.

Noting that $u_{1}^{n} \in R_{1}\left(x_{1}^{n}\right)$, it follows that

$$
\begin{aligned}
d\left(\bar{u}_{1}, R_{1}\left(x_{1}^{n}\right)\right) & \leq\left\|\bar{u}_{1}-u_{1}^{n}\right\|_{1}+d\left(u_{1}^{n}, R_{1}\left(x_{1}^{n}\right)\right)+\mathscr{\ell}_{1}\left(R_{1}\left(x_{1}^{n}\right), R_{1}\left(\bar{x}_{1}\right)\right) \\
& \leq\left\|\bar{u}_{1}-u_{1}^{n}\right\|_{1}+k_{1}\left\|\bar{x}_{1}-x_{1}^{n}\right\|_{1} \longrightarrow 0 \quad \text { as } n \longrightarrow \infty
\end{aligned}
$$

Hence, we must have $\bar{u}_{1} \in R_{1}\left(\bar{x}_{1}\right)$. Similarly, one can show that $\bar{u}_{2} \in R_{2}\left(\bar{x}_{1}\right), \bar{v}_{1} \in A_{1}\left(\bar{x}_{2}\right)$, and $\bar{v}_{2} \in A_{2}\left(\bar{x}_{2}\right)$. By Algorithm 3.4, we have that, for all $i \in I$,

$$
\begin{gathered}
\rho_{i}^{n+1}\left[F_{i}\left(x_{i}^{n+1}, y_{i}\right)+\left\langle N_{i}\left(u_{i}^{n}, v_{i}^{n}\right)-w_{i}, \eta_{i}\left(y_{i}, x_{i}^{n+1}\right)\right\rangle_{i}+\psi\left(x_{i}^{n+1}, y_{i}\right)-\psi\left(x_{i}^{n+1}, x_{i}^{n+1}\right)\right] \\
+\left\langle T_{i}\left(y_{i}\right)-T_{i}\left(x_{i}^{n+1}\right), x_{i}^{n+1}-x_{i}^{n}\right\rangle \geq 0 \quad \forall y_{i} \in K_{i}, n=0,1,2, \ldots
\end{gathered}
$$

Since $N_{i}$ is $\left(\beta_{i}, \xi_{i}\right)$-mixed Lipschitz continuous and $\eta_{i}$ is continuous in the second argument, one has, for each $y_{i} \in K_{i}$,

$$
\begin{aligned}
& \left|\left\langle N_{i}\left(u_{i}^{n}, v_{i}^{n}\right)-w_{i}, \eta_{i}\left(y_{i}, x_{i}^{n+1}\right)\right\rangle_{i}-\left\langle N_{i}\left(\bar{u}_{i}, \bar{v}_{i}\right)-w_{i}, \eta_{i}\left(y_{i}, \bar{x}_{i}\right)\right\rangle_{i}\right| \\
& \quad \leq\left|\left\langle N_{i}\left(u_{i}^{n}, v_{i}^{n}\right)-N_{i}\left(\bar{u}_{i}, \bar{v}_{i}\right), \eta_{i}\left(y_{i}, x_{i}^{n+1}\right)\right\rangle_{i}\right|+\left|\left\langle N_{i}\left(\bar{u}_{i}, \bar{v}_{i}\right)-w_{i}, \eta_{i}\left(y_{i}, x_{i}^{n+1}\right)-\eta_{i}\left(y_{i}, \bar{x}_{i}\right)\right\rangle_{i}\right| \\
& \quad \leq\left\|N_{i}\left(u_{i}^{n}, v_{i}^{n}\right)-N_{i}\left(\bar{u}_{i}, \bar{v}_{i}\right)\right\|\left\|\eta_{i}\left(y_{i}, x_{i}^{n+1}\right)\right\|+\left|\left\langle N_{i}\left(\bar{u}_{i}, \bar{v}_{i}\right)-w_{i}, \eta_{i}\left(y_{i}, x_{i}^{n+1}\right)-\eta_{i}\left(y_{i}, \bar{x}_{i}\right)\right\rangle_{i}\right| .
\end{aligned}
$$

Hence,

$$
\left|\left\langle N_{i}\left(u_{i}^{n}, v_{i}^{n}\right)-w_{i}, \eta_{i}\left(y_{i}, x_{i}^{n+1}\right)\right\rangle_{i}-\left\langle N_{i}\left(\bar{u}_{i}, \bar{v}_{i}\right)-w_{i}, \eta_{i}\left(y_{i}, \bar{x}_{i}\right)\right\rangle_{i}\right| \longrightarrow 0 \quad \text { as } n \longrightarrow \infty
$$


From the monotonicity of $F_{i}$ and the linearity of $T_{i}$, one has

$$
\begin{aligned}
& \left\langle N_{i}\left(u_{i}^{n}, v_{i}^{n}\right)-w_{i}, \eta_{i}\left(y_{i}, x_{i}^{n+1}\right)\right\rangle_{i}-\left\langle N_{i}\left(\bar{u}_{i}, \bar{v}_{i}\right)-w_{i}, \eta_{i}\left(y_{i}, \bar{x}_{i}\right)\right\rangle_{i} \\
& \quad+\psi_{i}\left(x_{i}^{n+1}, y_{i}\right)-\psi_{i}\left(x_{i}^{n+1}, x_{i}^{n+1}\right)+\frac{\left\|T_{i}\right\|}{\rho_{i}^{n+1}}\left\|y_{i}-x_{i}^{n+1}\right\|\left\|x_{i}^{n+1}-x_{i}^{n}\right\| \\
& \quad \geq F_{i}\left(y_{i}, x_{i}^{n+1}\right)-\left\langle N_{i}\left(\bar{u}_{i}, \bar{v}_{i}\right)-w_{i}, \eta_{i}\left(y_{i}, \bar{x}_{i}\right)\right\rangle_{i} \quad \forall y_{i} \in K_{i}, \forall n=0,1,2, \ldots
\end{aligned}
$$

Taking into account result (3.35) and since, for each $i \in I, F_{i}(y, \cdot)$ is a lower semicontinuous function, $\psi_{i}$ is continuous, and the sequence $\left\{x_{i}^{n}\right\}$ converges strongly to $\bar{x}_{i}$, it follows from relation (3.36) by passing to the limit when $n$ goes to infinity that

$$
\psi_{i}\left(y_{i}, \bar{x}_{i}\right)-\psi_{i}\left(\bar{x}_{i}, \bar{x}_{i}\right) \geq F_{i}\left(y_{i}, \bar{x}_{i}\right)-\left\langle N_{i}\left(\bar{u}_{i}, \bar{v}_{i}\right)-w_{i}, \eta_{i}\left(y_{i}, \bar{x}_{i}\right)\right\rangle_{i}
$$

Now, for each $i \in I$ and for $t \in(0,1]$ and $y_{i} \in K_{i}$, set $y_{i}(t)=t y_{i}+(1-t) \bar{x}_{i}$. Since $K_{i}$ is convex, then $y_{i}(t) \in K_{i}$ for $t \in(0,1]$; it follows that

$$
\left\langle N_{i}\left(\bar{u}_{i}, \bar{v}_{i}\right)-w_{i}, \eta_{i}\left(y_{i}(t), \bar{x}_{i}\right)\right\rangle_{i}+\psi_{i}\left(y_{i}(t), \bar{x}_{i}\right)-\psi_{i}\left(\bar{x}_{i}, \bar{x}_{i}\right) \geq F_{i}\left(y_{i}(t), \bar{x}_{i}\right) .
$$

Taking into account the convexity of $\psi_{i}\left(\cdot, \bar{x}_{i}\right)$, the fact that $N_{i}$ is affine with respect to the first argument and $\eta_{i}\left(\bar{x}_{i}, \bar{x}_{i}\right)=0$, one has

$$
F_{i}\left(y_{i}(t), \bar{x}_{i}\right) \leq t\left(\psi_{i}\left(y_{i}, \bar{x}_{i}\right)-\psi_{i}\left(\bar{x}_{i}, \bar{x}_{i}\right)\right)+t\left\langle N_{i}\left(\bar{u}_{i}, \bar{v}_{i}\right)-w_{i}, \eta_{i}\left(y_{i}, \bar{x}_{i}\right)\right\rangle_{i}
$$

On the other hand, since $F_{i}\left(x_{i}, x_{i}\right)=0$ for each $x_{i} \in K_{i}$ and $F_{i}\left(y_{i}, \cdot\right)$ is convex, it follows that

$$
0 \leq F_{i}\left(y_{i}(t), y_{i}(t)\right) \leq t F_{i}\left(y_{i}(t), y_{i}\right)+(1-t) F\left(y_{i}(t), \bar{x}_{i}\right)
$$

Hence, from relation (3.39), one has

$$
0 \leq t\left[F_{i}\left(y_{i}(t), y_{i}\right)+(1-t)\left(\psi_{i}\left(y_{i}, \bar{x}_{i}\right)-\psi_{i}\left(\bar{x}_{i}, \bar{x}_{i}\right)+\left\langle N_{i}\left(\bar{u}_{i}, \bar{v}_{i}\right)-w_{i}, \eta_{i}\left(y_{i}, \bar{x}_{i}\right)\right\rangle_{i}\right)\right]
$$

Therefore, for all $t \in] 0,1]$, one has

$$
0 \leq F_{i}\left(y_{i}(t), y_{i}\right)+(1-t)\left(\psi_{i}\left(y_{i}, \bar{x}_{i}\right)-\psi_{i}\left(\bar{x}_{i}, \bar{x}_{i}\right)+\left\langle N_{i}\left(\bar{u}_{i}, \bar{v}_{i}\right)-w_{i}, \eta_{i}\left(y_{i}, \bar{x}_{i}\right)\right\rangle_{i}\right)
$$

Since for each $y_{i} \in K_{i}, x \mapsto F_{i}(x, y)$ is upper hemicontinuous, it follows by passing to limit when $t \rightarrow 0$ in the previous inequality that

$$
F_{i}\left(\bar{x}_{i}, y_{i}\right)+\left\langle N_{i}\left(\bar{u}_{i}, \bar{v}_{i}\right)-w_{i}, \eta_{i}\left(y_{i}, \bar{x}_{i}\right)\right\rangle_{i}+\psi_{i}\left(\bar{x}_{i}, y_{i}\right)-\psi_{i}\left(\bar{x}_{i}, \bar{x}_{i}\right) \geq 0 \quad \forall y_{i} \in K_{i}
$$

which completes the proof. 


\section{Commentaries}

In conclusion, the approach used in this paper lets us improve and extend some new results in literature related to the problem studied. To be more precise,

(1) Theorems 3.2 and 3.5 improve recent results given by Ding [18, Theorem 3.1, Theorem 4.1], since the bifunction $F_{i}$ is not needed to be $\delta_{i}$-Lipschitz continuous nor weakly upper semicontinuous with respect to the first argument in all steps of the procedure, firstly when dealing with the existence of solutions for the auxiliary problem and secondly when studying the convergence of the algorithm;

(2) we mention also that all the results obtained in [18] are under the assumption $\operatorname{int}\left\{y_{i} \in K_{i}, \psi_{i}\left(y_{i}, y_{i}\right)<\infty\right\}=\operatorname{int} K_{i} \neq \emptyset$; in our approach, this assumption is not needed;

(3) in the special case where $F_{i} \equiv 0$, the results obtained improve those obtained by Ding and Wang [17], since the assumptions on the bifunctions $\psi_{i}$ have been relaxed.

\section{References}

[1] C. Baiocchi and A. Capelo, Variational and Quasivariational Inequalities: Applications to Free Boundary Problems, John Wiley \& Sons, New York, NY, USA, 1984.

[2] E. Blum and W. Oettli, "From optimization and variational inequalities to equilibrium problems," The Mathematics Student, vol. 63, no. 1-4, pp. 123-145, 1994.

[3] I. Konnov, "Generalized monotone equilibrium problems and variational inequalities," in Handbook of Generalized Convexity and Generalized Monotonicity, Nonconvex Optimization and Applications, N. Hadjisavvas, S. Komlosi, and S. Schaible, Eds., pp. 559-618, Springer, New York, NY, USA, 2005.

[4] M. Patriksson, Nonlinear Programming and Variational Inequality Problems: a unified approach, Kluwer Academic Publishers, Dordrecht, The Netherlands, 1999.

[5] A. Bnouhachem and M. A. Noor, "A new iterative method for variational inequalities," Applied Mathematics and Computation, vol. 182, no. 2, pp. 1673-1682, 2006.

[6] P. L. Combettes and S. A. Hirstoaga, "Equilibrium programming using proximal-like algorithms," Mathematical Programming, vol. 78, no. 1, pp. 29-41, 1997.

[7] X.-F. He, J. Chen, and Z. He, "Generalized projection method for a variational inequality system with different mapping in Banach spaces," Computers $\mathcal{E}$ Mathematics with Applications, vol. 58, no. 7, pp. 1391-1396, 2009.

[8] B.-S. He, Z.-H. Yang, and X.-M. Yuan, “An approximate proximal-extragradient type method for monotone variational inequalities," Journal of Mathematical Analysis and Applications, vol. 300, no. 2, pp. 362-374, 2004.

[9] A. Moudafi and M. Théra, "Proximal and dynamical approaches to equilibrium problems," in Lecture Notes in Economics and Mathematical Systems, vol. 477, pp. 187-201, Springer, Berlin, Germany, 1999.

[10] M. A. Noor, "Projection-proximal methods for general variational inequalities," Journal of Mathematical Analysis and Applications, vol. 318, no. 1, pp. 53-62, 2006.

[11] R. U. Verma, "General convergence analysis for two-step projection methods and applications to variational problems," Applied Mathematics Letters, vol. 18, no. 11, pp. 1286-1292, 2005.

[12] X. P. Ding, "Existence of solutions and an algorithm for mixed variational-like inequalities in Banach spaces," Journal of Optimization Theory and Applications, vol. 127, no. 2, pp. 285-302, 2005.

[13] X. P. Ding, J.-C. Yao, and L.-C. Zeng, "Existence and algorithm of solutions for generalized strongly nonlinear mixed variational-like inequalities in Banach spaces," Computers $\mathcal{E}$ Mathematics with Applications, vol. 55, no. 4, pp. 669-679, 2008.

[14] G. Mastroeni, “On auxiliary principle for equilibrium problems," in Equilibrium Problems and Variational Models, P. Daniele, F. Giannessi, and A. Maugeri, Eds., pp. 289-298, Kluwer, Dordrecht, The Netherlands, 2003.

[15] L. C. Zeng, S. Schaible, and J. C. Yao, "Iterative algorithm for generalized set-valued strongly nonlinear mixed variational-like inequalities," Journal of Optimization Theory and Applications, vol. 124, no. 3, pp. 725-738, 2005. 
[16] K. R. Kazmi and F. A. Khan, "Auxiliary problems and algorithm for a system of generalized variational-like inequality problems," Applied Mathematics and Computation, vol. 187, no. 2, pp. 789-796, 2007.

[17] X. P. Ding and Z. B. Wang, "The auxiliary principle and an algorithm for a system of generalized set-valued mixed variational-like inequality problems in Banach spaces," Journal of Computational and Applied Mathematics, vol. 233, no. 11, pp. 2876-2883, 2010.

[18] X.-P. Ding, "Auxiliary principle and approximation solvability for system of new generalized mixed equilibrium problems in reflexive Banach spaces," Journal of Applied Mathematics and Mechanics, vol. 32, no. 2, pp. 231-240, 2011.

[19] B. S. Mordukhovich, B. Panicucci, M. Pappalardo, and M. Passacantando, "Hybrid proximal methods for equilibrium problems," Optimization Letters. In press.

[20] A. S. Antipin, "Computation of fixed points of extremal mappings by means of gradient-type methods," Zhurnal Vychislitel cprime noй Matematiki i Matematicheskoŭ Fiziki, vol. 37, no. 1, pp. 42-53, 1997.

[21] O. Chadli, Z. Chbani, and H. Riahi, "Equilibrium problems with generalized monotone bifunctions and applications to variational inequalities," Journal of Optimization Theory and Applications, vol. 105, no. 2, pp. 299-323, 2000.

[22] S. B. Nadler,, "Multi-valued contraction mappings," Pacific Journal of Mathematics, vol. 30, pp. 475-488, 1969. 


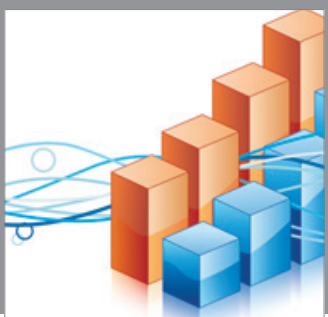

Advances in

Operations Research

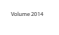

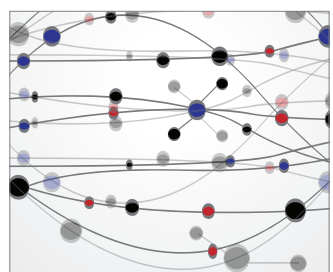

\section{The Scientific} World Journal
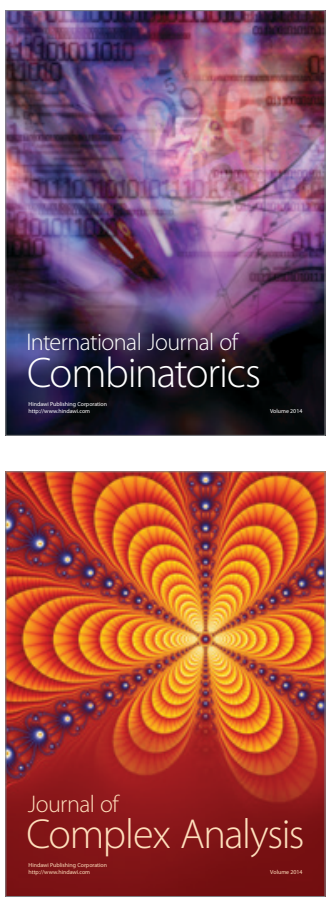

International Journal of

Mathematics and

Mathematical

Sciences
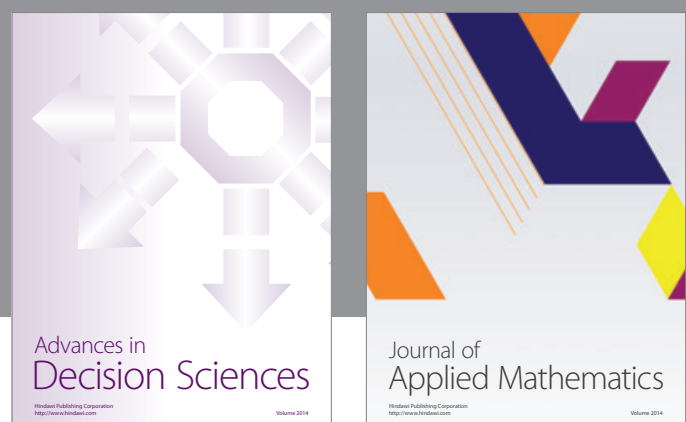

Journal of

Applied Mathematics
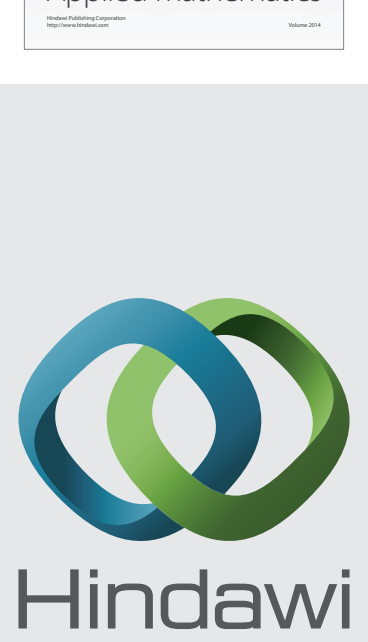

Submit your manuscripts at http://www.hindawi.com
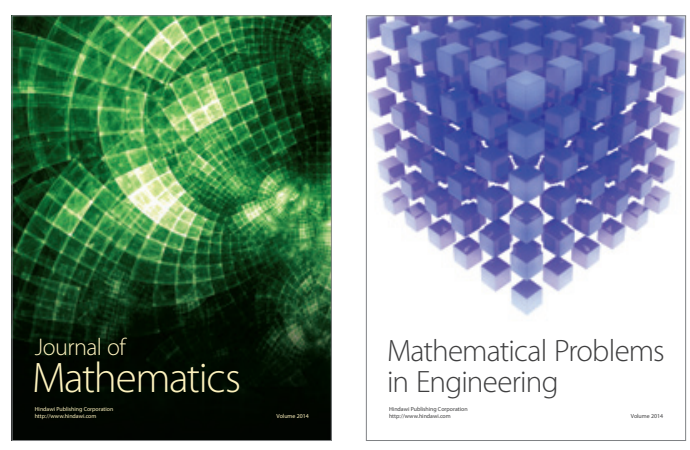

Mathematical Problems in Engineering
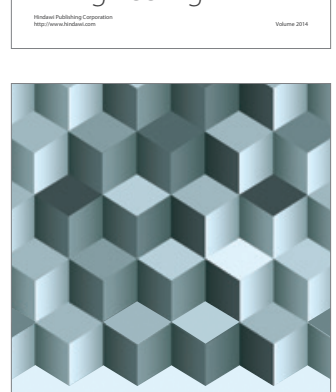

Journal of

Function Spaces
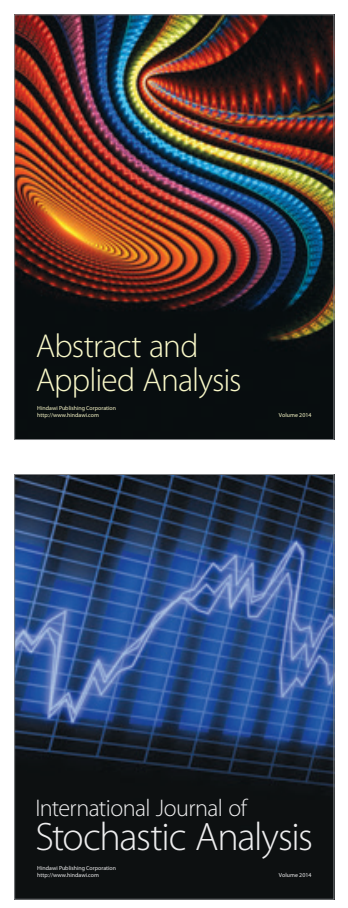

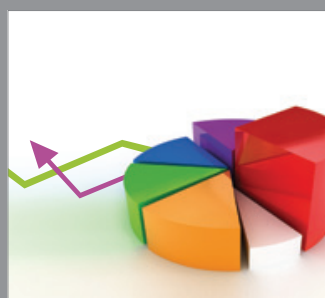

ournal of

Probability and Statistics

Promensencen
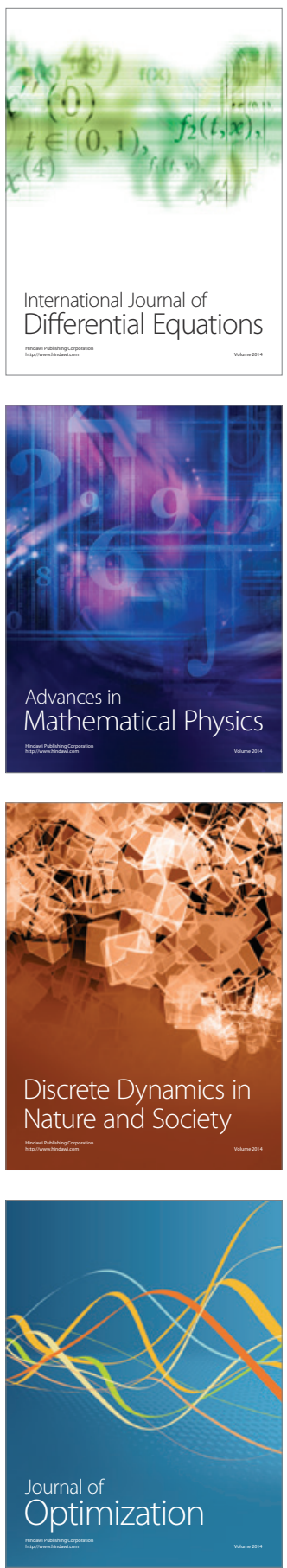